\title{
Review
}

\section{The Achievement of Shuttle Vector Techniques in Mammalian Cell Mutation Research}

\author{
Takashi Yagi ${ }^{1}$ \\ Department of Biology, Graduate School of Science, Osaka Prefecture University, Osaka, Japan, and \\ Department of Life Science, Dongguk University Seoul, Seoul, Korea
}

Received March 16, 2013; Revised April 20, 2013; Accepted April 22, 2013

J-STAGE Advance published date: July 1, 2013

\begin{abstract}
Shuttle vector plasmids have made major contributions to the advancement of mutation research for the last two decades. I have been involved in the development of shuttle vector plasmids and their experimental protocols, and herein provide a chronicle of shuttle vector studies. In the late 1960s, in vitro mammalian cell culture became a common technique in cell biology. Geneticists established a method to detect gene mutation as 8-azaguanine or 6-thioguanine resistance after cells had been exposed to radiation or chemicals. The resistance of the cells was found to be due to a mutation of the hypoxanthine-guanine phosphoribosyl transferase gene; however, which base was changed in the gene remained difficult to determine until DNA sequencing techniques were developed. After the Sanger method of DNA sequencing became available to geneticists, the next issue was how to identify numerous base changes in mutants easily and rapidly. A breakthrough on this issue was the use of the shuttle vector plasmid pZ189, which was developed for practical applications by Seidman and colleagues. Along with the development of new molecular biology techniques such as polymerase chain reaction and automatic DNA sequencing, pZ189 has been modified to several forms as adaptations to the new techniques. These shuttle vector plasmids remain useful tools to reveal what types of mutations are induced by newly identified mutagens at the DNA sequence level. This article describes some of the contents of my JEMS award lecture in 2011.
\end{abstract}

Key words: mutation, shuttle vector plasmid, supF, pZ189, pMY189, pNY200

\section{Introduction: A Chronicle of Methods in Mutation Research}

In the early $1960 \mathrm{~s}$, in vitro culture of mammalian cells was established, although by then bacterial genetics had already been prospering for a long time. Scientists attempted to study genetics using the cultures of mammalian cells, as with bacteria, and mutation induction was first demonstrated as 8-azaguanine resistance by alkylating agents in Chinese hamster V79 cells (1). Sato,
Slesinsli and Littlefield (2) measured the frequencies of 6-thioguanine resistant mutations induced by alkylating agents in cultured human lymphoblastoid cells. Subsequently, studies on 8-azaguanine- and 6-thioguanineresistant mutations induced by various chemicals and types of radiations became common among geneticists who soon found that these mutations were induced in the hypoxanthine-guanine phosphoribosyl transferase gene (hprt). The development of the Sanger method of DNA base sequencing allowed the identification of mutated bases in the late 1970s $(3,4)$; however, the method was very complex and laborious in terms of identifying the base changes of many mutants.

For the rapid identification of many mutations at the base sequence level, geneticists developed shuttle vector plasmids that carry mutation and selection marker genes and can replicate in both mammalian and Escherichia coli cells. One of the reliable and practical plasmids is pZ189, which was developed by Seidman et al. (5). The plasmid pZ189 has the bacterial supF gene as a mutation target, and the gene is about $160 \mathrm{bp}$, which is short enough to read all base sequences with a ${ }^{32} \mathrm{P}$-label by one run on a polyacrylamide gel sequencing plate. $E$. coli with the supF gene mutated in human cells is easily selected as a colony on an agar plate. In this way, pZ189 constituted major progress in revealing the mutational spectra of various mutagens. The details of this are described in the next section.

The invention of the polymerase chain reaction (PCR) was a breakthrough in mutation research $(6,7)$. Mutations of hprt cDNA of ethyl nitrosourea-induced 6-thioguanine-resistant cells were identified at the base sequence level with reverse transcriptase PCR (RTPCR) and ${ }^{32} \mathrm{P}$-labeling DNA sequencing methods (8). $\mathrm{Yu}$ et al. (9) identified base changes of the hprt gene by

${ }^{1}$ Correspondence to: Takashi Yagi, Department of Biology, Graduate School of Science, Osaka Prefecture University, 1-2 Gakuen-cho, Naka-ku, Sakai, Osaka 599-8570, Japan. Tel: +81-72-254-9862, Fax: +82-72-254-9938, E-mail: yagi-t@riast.osakafu-u.ac.jp doi: org/10.3123/jemsge.2013.001 
the multiplex PCR method. In the 1990s, automatic DNA sequencing was developed and adapted in genetic research $(10,11)$. The combination of PCR and automatic DNA sequencing has promoted the molecular study of chemical and radiation mutagenesis up until the present. The shuttle vector plasmid pZ189 has also been improved with the progress of these new techniques, as described below.

In the 1990s, in vivo mutation assays using shuttle vector transgenic mice were established. The transgenic mice called Mutamouse and Big Blue mouse, possessing bacterial lacZ and lacI genes, respectively, can be treated with chemicals or radiation, and the mutation target transgenes can then be recovered from the mouse cells into plaques of bacteriophage $\lambda(12,13)$. Nohmi et al. (14) also established a new transgenic mouse carrying the bacterial gpt $\Delta$ gene that can be recovered into bacteriophage $\lambda$. This gpt $\Delta$ assay system was adopted as the in vivo mutation assay in the OECD guidelines (15).

\section{Development of the First Practical Shuttle Vector Plasmid pZ189}

The shuttle vector plasmid pZ189 developed by Sedman et al. (5) was extensively characterized by his colleagues, namely, Razzaque A, Dixon K, Bredberg A, Seetharam $\mathrm{S}$ and Kraemer $\mathrm{KH}$, who belonged to the laboratory of Molecular Carcinogenesis, National Cancer Institute, NIH. I was a member of the laboratory from 1982 to 1984 . The plasmid pZ189 contains the following elements: the $T$ antigen coding region and origin of replication from the SV40 virus; the ampicillinresistance gene $\left(\mathrm{Ap}^{\mathrm{R}}, A m p\right)$, the pBR327 origin of replication (pBR327 ori); the suppressor tRNA (supF) gene that serves as the mutagenesis marker; and the IG region from the bacteriophage M13 DNA to permit the production of single-stranded plasmid DNA in M13infected cells. The supF tRNA gene with regulatory regions consists of about $160 \mathrm{bp}$ and lies between two essential components of the plasmid, the $A m p$ gene and the ori of the plasmid.

The plasmid treated with a mutagen was propagated in human cells for $48-72 \mathrm{~h}$. The plasmid was extracted from the cells, and then digested by the restriction endonuclease $D p n I$ to eliminate non-replicated input plasmids with the bacterial methylation pattern. E. coli MBM7070, which has an amber mutation in its lacZ gene [lacZ(am)CA7020], was transformed by the plasmid and spread onto LB agar plates containing ampicillin, 5-bromo-4-chloro-3-indoyl- $\beta$-D-galactoside (X-gal) and isopropyl- $\beta$-D-thiogalactoside (IPTG). After $24 \mathrm{~h}$ incubation at $37^{\circ} \mathrm{C}$, blue colonies having normal sup $\mathrm{F}$ and white or light-blue colonies having mutated supF appeared on the plate. The total number of colonies was counted as an indication of plasmid survival, and the proportion of white or light-blue colonies was deter- mined as a measure of mutant frequency. The sup F gene of the white or light-blue colonies was sequenced to reveal which base had been mutated by the mutagen.

\section{Modification of the Shuttle Vector Plasmid}

The first automatic DNA sequencer with a reliable DNA sequencing reagent kit was distributed by Applied Biosystems Inc. (ABI) (16). The - M13 primer, whose 5 '-end had been labeled with fluorescent dye, became the standard primer (Dye-primer) for sequencing with ABI Model 373. Matsuda et al. (17) synthesized a 13-mer oligonucleotide sequence that can hybridize with the fluorescent -M13 primer, and inserted it into the EcoRI site of pZ189. The plasmid was named pMY189 (Fig. 1A). To propagate pMY189 in rodent cells, a part of the pMY189 sequence derived from SV40 was replaced by the whole genome of polyoma virus, and the plasmid was called pYZ289 (18). An unnecessary part of the polyoma virus sequence of pYZ289 for plasmid replication was removed by Nakayama et al. (19), and finally the plasmid pNY200 for rodent cells was established as a counterpart of pMY189 for human cells (Fig. 1B). Both shuttle vector plasmids were applied for the ABI Dye-primer sequencing and later for Dye-terminator sequencing, according to technical innovations of automatic DNA sequencing.

In the shuttle vector plasmid assay, there has been a fundamental issue that mutants arising from an independent event cannot be distinguished from siblings of an initial event when an identical base change appears from a plasmid transfection plate. Parris and Seidman (20) resolved this issue by developing a population system, pSP189 plasmids, each of which contains an 8-bp 'signature sequence'. This sequence confers a unique identification tag to each plasmid and allows individual members to be identified by a distinctive signature. This system is particularly advantageous when low mutant frequencies are obtained by weak mutagen treatment.

As indicator bacteria for sup $\mathrm{F}$ mutation, E. coli KS40/pKY241 was established (21) instead of the MBM7070 strain. The E. coli KS40 has a MBM7070

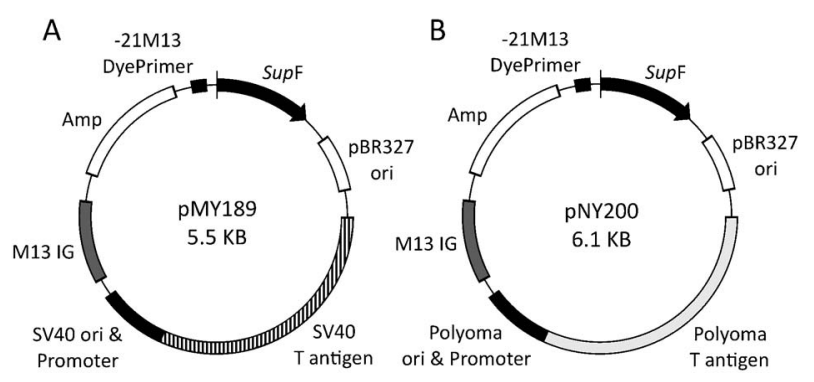

Fig. 1. Shuttle vector plasmids, pMY189 (A) and pNY200 (B), that can replicate in human and mouse cells, respectively. These plasmids can also replicate and undergo selection of their supF mutations in $E$. coli. 
derivative that has a DNA gyrase A ( gyrA) gene with an amber mutation, and the plasmid pKY241 has a wildtype gyrA gene and a chloramphenicol-resistant marker gene. The E. coli carrying pKY241 is therefore resistant to nalidixic acid and chloramphenicol. The bacteria carrying pKY241 and pMY189 with wild-type supF cannot make colonies on an LB agar plate containing nalidixic acid, ampicillin and chloramphenicol, whereas those carrying pKY241 and pMY189 with mutated supF can. The addition of IPTG and X-gal in the plate can confirm the selection of the mutated supF gene by the color of the colonies, like the MBM7070 strain. The E. coli $\mathrm{KS} 40 / \mathrm{pKY} 241$ strain increased accuracy of measurement of sup $\mathrm{F}$ mutant frequencies.

\section{Application of the Shuttle Vector Plasmids to UV Mutagenesis}

As soon as the plasmid pZ189 became available (5), a series of studies to elucidate the mutation spectrum of ultraviolet light (UV) in human cells were carried out by Kraemer and colleagues (22-25). UV was the first subject of the studies because UV-induced DNA damage, cyclobutane pyrimidine dimers (CPDs) and 6-4 photoproducts (6-4 PPs), had been well characterized and the DNA repair-deficient cells derived from xeroderma pigmentosum (XP) patients with 7 genetic complementation groups were by then available. The lesions induced in pZ189 by UV irradiation in vitro are not removed in XP cells, and therefore, all lesions become triggers of mutations upon plasmid replication in $\mathrm{XP}$ cells.

As a result of various studies on UV-induced mutations in the shuttle vector plasmids introduced into normal human and XP cells (22-27), some key findings that are now common knowledge were obtained. The G:C to $\mathrm{A}: \mathrm{T}$ transition is the major type of UV-induced mutation, and its frequency is higher in DNA repair-deficient $\mathrm{XP}$ cells than in normal human cells. The $\mathrm{C}$ to $\mathrm{T}$ transitions occur mostly at the $3^{\prime}-\mathrm{C}$ of $5^{\prime}-\mathrm{TC}-3^{\prime}$ and $5^{\prime}-\mathrm{CC}-3^{\prime}$ sequences. Tandem CC to TT transitions at $5^{\prime}-\mathrm{CC}-3^{\prime}$ sequences are also a feature of UV-induced mutation. The most abundant DNA lesion, cyclobutane thymine dimer, which is expected to cause base substitution at $5^{\prime}$-TT-3' sequences, is not a premutagenic lesion $(28,29)$. More precise analysis exploiting photoreactivating enzymes, CPDs and 6-4 PPs photolyases, following UV irradiation to the shuttle vector plasmid was carried out by Otoshi et al. (30). They revealed that both cytosine-containing CPDs and 6-4 PPs are premutagenic lesions for $\mathrm{G}: \mathrm{C}$ to $\mathrm{A}: \mathrm{T}$ transitions, while the premutagenic lesions for A:T to G:C transitions are 6-4 PPs.

A tumor suppressor gene, $p 53$, has been studied extensively; these studies revealed that more than $50 \%$ of human tumors including skin tumors have mutations in the $p 53$ gene $(31,32)$. XP patients are predisposed to skin tumors because they are deficient in the ability to repair UV-induced DNA lesions. Identification of base changes in the $p 53$ gene of XP skin tumors revealed that predominant base changes are $\mathrm{C}$ to $\mathrm{T}$ transitions at the $3^{\prime}-\mathrm{C}$ of $5^{\prime}-\mathrm{TC}-3^{\prime}$ and $5^{\prime}-\mathrm{CC}-3^{\prime}$ sequences, and tandem $\mathrm{CC}$ to TT transitions at $5^{\prime}-\mathrm{CC}-3^{\prime}$ sequences have also been characterized (33-35). Similar types of $p 53$ base changes are also found in the skin tumors of sunexposed body areas, but not in skin tumors of nonexposed areas (36). These mutation characteristics are similar to those found in the UV-induced mutations of shuttle vectors, indicating that $p 53$ gene mutation is a cause of skin tumors induced by sunlight.

\section{Application of the Shuttle Vector Plasmids to Chemical Mutagenesis}

The shuttle vector plasmids have been applied to reveal the types of mutations induced by various chemical mutagens. $N$-methyl nitrosourea (MNU)-induced mutations in the plasmids were more frequent in $O^{6}$-methylguanine-DNA methyltransferase (MGMT)-deficient cells than in proficient cells (37). The G:C to A:T transition is dominant, particularly in MGMT-deficient cells, which agrees with the findings that unrepaired $O^{6}$ methylguanine can form a mispair with thymine at DNA replication $(38,39)$.

Carcinogenic polyaromatic hydrocarbons (PAHs) are emitted mainly by industry and automobiles, but most of them do not react with DNA directly. These PAHs are biotransformed to reactive intermediates by cellular metabolic enzymes. The reactive metabolites of the PAHs, 1-nitropyrene, benzo[a]pyrene (40), aminofluorene (41) and 3-nitrobenzanthrone $(42,43)$, make bulky DNA adducts in DNA. The bulky adducts formed in the shuttle vector plasmids yield mainly G:C to T:A transversions in human cells. Recent progress of translesion DNA polymerases ( $\mathrm{Pol} \eta, l, \kappa$ and $\zeta$ ) shows that $\mathrm{Pol} \eta$, the major polymerase for translesion DNA synthesis (TLS), predominantly inserts adenine opposite a guanine carrying such a bulky adduct $(44,45)$, which is consistent with the results from shuttle vector mutagenesis. This is also consistent with the A-rule of base misincorporation, which has been established in molecular genetics (46).

Various aldehydes such as acetaldehyde, 2-chloroacetaldehyde, crotonaldehyde, acrolein, glyoxal and methylglyoxal are formed in cells through the intake of food, drink and air. These aldehydes react with DNA and form exocyclic guanines, ethenoguanine and propanoguanine $(47,48)$. These DNA lesions generates mutations mainly at G:C sites, but the types of base change are different among these aldehydes in the shuttle vector assays (49-54). It is noteworthy that acetaldehyde induced tandem base changes at 5'-GG-3' sites, suggesting that it forms intra-strand crosslinks between 
adjacent guanines through propanodeoxyguanine formation (51).

Benzene is biotransformed to several products, muconic acid, $p$-benzoquinone, catechol and hydroquinone, in the body (55). Hydroquinone produces reactive oxygen species in cells. In the shuttle vector assay, hydroquinone induced deletion mutations frequently in the presence of $\mathrm{NADH}$ and $\mathrm{Cu}$ (II), which is consistent with the reaction of reactive oxygen species to DNA (56). Other benzene biotransformants were less mutagenic than hydroquinone $(19,56,57)$.

\section{Prospects for New Shuttle Vector Development to Study TLS}

TLS is a tolerance pathway of replication block caused by DNA lesions $(58,59)$. To measure the efficiency and fidelity of TLS in human cells, a new shuttle vector assay system was established recently (60). This assay consists of transfection of DNA repair-deficient human cells with a plasmid possessing a single DNA adduct, and transformation of indicator bacteria with plasmids extracted from the cells. The plasmid consists of SV40 replication origin, $\mathrm{T}$ antigen gene, bacterial Amp gene and lacZ gene, where a single site-specific DNA adduct is produced. The plasmid DNA strand with an adduct replicates by bypassing the adduct in human cells and forms a blue bacterial colony, whereas the other DNA strand that has a 2-base frameshift without the adduct replicates in human cells and forms a white bacterial colony. Replication of the plasmid possessing a single aminobiphenyl-dG adduct was suppressed to $1 / 9$ of that of the normal plasmid, and the mutant frequency of the TLS-operated plasmids was 0.31 , of which the major mutation $(78 \%$ ) was a $\mathrm{G}$ to $\mathrm{T}$ transversion (60). Using this assay system, we showed that a new inhibitor of proliferating cell nuclear antigen (PCNA) suppressed TLS of cisplatin-guanine adducts (61). These results demonstrate that this assay is applicable for investigating TLS in human cells. This cellular TLS assay is superior to the cell free TLS assay in a test tube using adducted oligonucleotide, extension primer and purified TLS polymerases because the in vitro test tube assay is less reflective of the cellular process. A project to measure TLS efficiencies and mutation frequencies of various DNA adducts formed by 3nitrobenzanthrone, a carcinogenic nitro-PAH from diesel exhaust, is in progress (62).

In conclusion, the shuttle vector assays that were improved by many investigators have been disclosing the mutation spectra of various chemical and physical mutagens in mammalian cells. These assays will further contribute to elucidate the TLS mechanism of various DNA adducts in human cells. The remaining issues are the elucidation of which TLS polymerase operates to bypass various kinds of DNA lesions, and what type of mutation is induced by each TLS polymerase in the cells. The clarification of mutation mechanisms at the molecular level would be important for studies on human cancer prevention.

Acknowledgments: The author thanks all instructors, collaborators and students who have provided support via their participation in the field of mutation research. The author would not have received the award and written this review without this earnest support. This research was supported by Grants in Aid for Scientific Research (B) No. 24310047 and for Challenging Exploratory Research No. 24651063 from the Japan Society for the Promotion of Science.

Conflicts of interest statement: The author declares that there are no conflicts of interest.

\section{References}

1 Chu EH, Malling HV. Mammalian cell genetics. II. Chemical induction of specific locus mutations in Chinese hamster cells in vitro. Proc Natl Acad Sci USA. 1968; 61: 1306-12.

2 Sato K, Slesinski RS, Littlefield JW. Chemical mutagenesis at the phosphoribosyltransferase locus in cultured human lymphoblasts. Proc Natl Acad Sci USA. 1972; 69: 1244-8.

3 Sanger F, Nicklen S, Coulson AR. DNA sequencing with chain-terminating inhibitors. Proc Natl Acad Sci USA. 1977; 74: 5463-7.

4 Sanger F, Coulson AR.FEBS Lett. The use of thin acrylamide gels for DNA sequencing. 1978; 87: 107-10.

5 Seidman MM, Dixon K, Razzaque A, Zagursky RJ, Berman ML. A shuttle vector plasmid for studying carcinogen-induced point mutations in mammalian cells. Gene. 1985; 38: 233-7.

6 Saiki RK, Scharf S, Faloona F, Mullis KB, Horn GT, Erlich HA, Arnheim N. Enzymatic amplification of betaglobin genomic sequences and restriction site analysis for diagnosis of sickle cell anemia. Science. 1985; 230: 1350-4.

7 Mullis KB, Faloona FA. Specific synthesis of DNA in vitro via a polymerase-catalyzed chain reaction. Methods Enzymol. 1987; 155: 335-50.

8 Vrieling H, Simons JW, van Zeeland AA. Nucleotide sequence determination of point mutations at the mouse HPRT locus using in vitro amplification of HPRT mRNA sequences. Mutat Res. 1988; 198: 107-13.

$9 \mathrm{Yu} \mathrm{YJ,} \mathrm{Xu} \mathrm{Z,} \mathrm{Gibbs} \mathrm{RA,} \mathrm{Hsie} \mathrm{AW.} \mathrm{Polymerase} \mathrm{chain}$ reaction-based comprehensive procedure for the analysis of the mutation spectrum at the hypoxanthine-guanine phosphoribosyltransferase locus in Chinese hamster cells. Environ Mol Mutagen. 1992; 19: 267-73.

10 Smith LM, Sanders JZ, Kaiser RJ, Hughes P, Dodd C, Connell CR, Heiner C, Kent SB, Hood LE. Fluorescence detection in automated DNA sequence analysis. Nature. 1986; 321: 674-9.

11 Ansorge W, Sproat B, Stegemann J, Schwager C, Zenke 
M. Automated DNA sequencing: ultrasensitive detection of fluorescent bands during electrophoresis. Nucleic Acids Res. 1987; 15: 4593-602.

12 Gossen JA, de Leeuw WJ, Tan $\mathrm{CH}$, Zwarthoff EC, Berends F, Lohman PH, Knook DL, Vijg J. Efficient rescue of integrated shuttle vectors from transgenic mice: a model for studying mutations in vivo. Proc Natl Acad Sci USA. 1989; 86: 7971-5.

13 Kohler SW, Provost GS, Fieck A, Kretz PL, Bullock WO, Sorge JA, Putman DL, Short JM. Spectra of spontaneous and mutagen-induced mutations in the lacI gene in transgenic mice. Proc Natl Acad Sci USA. 1991; 88: 7958-62.

14 Nohmi T, Katoh M, Suzuki H, Matsui M, Yamada M, Watanabe M, Suzuki M, Horiya N, Ueda O, Shibuya T, Ikeda $\mathrm{H}$, Sofuni $\mathrm{T}$. A new transgenic mouse mutagenesis test system using Spi- and 6-thioguanine selections. Environ Mol Mutagen. 1996; 28: 465-70.

15 OECD. OECD Guidelines for the Testing of Chemicals, Section 4: Health Effects Test No. 488: Transgenic Rodent Somatic and Germ Cell Gene Mutation Assays. UK: OECD Publishing; 2011.

16 Halloran N, Du Z, Wilson RK. Sequencing reactions for the applied biosystems 373A Automated DNA Sequencer. Methods Mol Biol. 1993; 23: 297-315.

17 Matsuda T, Yagi T, Kawanishi M, Matsui S, Takebe H. Molecular analysis of mutations induced by 2-chloroacetaldehyde, the ultimate carcinogenic form of vinyl chloride, in human cells using shuttle vectors. Carcinogenesis. 1995; 16: 2389-94.

18 Yagi T, Sato M, Nishigori C, Takebe H. Similarity in the molecular profile of mutations induced by UV light in shuttle vector plasmids propagated in mouse and human cells. Mutagenesis. 1994; 9: 73-7.

19 Nakayama A, Kawanishi M, Takebe H, Morisawa S, Yagi T. Molecular analysis of mutations induced by a benzene metabolite, $p$-benzoquinone, in mouse cells using a novel shuttle vector plasmid. Mutat Res. 1999; 444: 123-31.

20 Parris CN, Seidman MM. A signature element distinguishes sibling and independent mutations in a shuttle vector plasmid. Gene. 1992; 117: 1-5.

21 Akasaka S, Takimoto K, Yamamoto K. G:C $\rightarrow$ T:A and $\mathrm{G}: \mathrm{C} \rightarrow \mathrm{C}: \mathrm{G}$ transversions are the predominant spontaneous mutations in the Escherichia coli sup F gene: an improved lacZ(am) E. coli host designed for assaying pZ189 supF mutational specificity. Mol Gen Genet. 1992; 235: 173-8.

22 Bredberg A, Kraemer KH, Seidman MM. Restricted ultraviolet mutational spectrum in a shuttle vector propagated in xeroderma pigmentosum cells. Proc Natl Acad Sci USA. 1986; 83: 8273-7.

23 Seetharam S, Protić-Sabljić M, Seidman MM, Kraemer KH. Abnormal ultraviolet mutagenic spectrum in plasmid DNA replicated in cultured fibroblasts from a patient with the skin cancer-prone disease, xeroderma pigmentosum. J Clin Invest. 1987; 80: 1613-7.

24 Seetharam S, Kraemer KH, Waters HL, Seidman MM. Mutational hotspot variability in an ultraviolet-treated shuttle vector plasmid propagated in xeroderma pigmentosum and normal human lymphoblasts and fibroblasts. J Mol Biol. 1990; 212: 433-6.

25 Seetharam S, Kraemer KH, Waters HL, Seidman MM. Ultraviolet mutational spectrum in a shuttle vector propagated in xeroderma pigmentosum lymphoblastoid cells and fibroblasts. Mutat Res. 1991; 254: 97-105.

26 Yagi T, Tatsumi-Miyajima J, Sato M, Kraemer KH, Takebe H. Analysis of point mutations in an ultravioletirradiated shuttle vector plasmid propagated in cells from Japanese xeroderma pigmentosum patients in complementation groups A and F. Cancer Res. 1991; 51: 3177-82.

27 Yagi T, Sato M, Tatsumi-Miyajima J, Takebe H. UV-induced base substitution mutations in a shuttle vector plasmid propagated in group $\mathrm{C}$ xeroderma pigmentosum cells. Mutat Res. 1992; 273: 213-20.

28 Pfeifer GP, You YH, Besaratinia A. Mutations induced by ultraviolet light. Mutat Res. 2005; 571: 19-31.

29 Ikehata H, Ono T. The mechanisms of UV mutagenesis. J Radiat Res. 2011; 52: 115-25.

30 Otoshi E, Yagi T, Mori T, Matsunaga T, Nikaido O, Kim ST, Hitomi K, Ikenaga M, Todo T. Respective roles of cyclobutane pyrimidine dimers, (6-4)photoproducts, and minor photoproducts in ultraviolet mutagenesis of repairdeficient xeroderma pigmentosum A cells. Cancer Res. 2000; 60: 1729-35.

31 Soussi T. p53 alterations in human cancer: more questions than answers. Oncogene. 2007; 26: 2145-56.

32 Pfeifer GP, Besaratinia A. Mutational spectra of human cancer. Hum Genet. 2009; 125: 493-506.

33 Sato $M$, Nishigori $C$, Zghal $M$, Yagi $T$, Takebe $H$. Ultraviolet-specific mutations in p53 gene in skin tumors in xeroderma pigmentosum patients. Cancer Res. 1993; 53: 2944-6.

34 Matsumura Y, Sato M, Nishigori C, Zghal M, Yagi T, Imamura $\mathrm{S}$, Takebe $\mathrm{H}$. High prevalence of mutations in the p53 gene in poorly differentiated squamous cell carcinomas in xeroderma pigmentosum patients. J Invest Dermatol. 1995; 105: 399-401.

35 Giglia-Mari G, Sarasin A. TP53 mutations in human skin cancers. Hum Mutat. 2003; 21: 217-28.

36 Matsumura Y, Nishigori C, Yagi T, Imamura S, Takebe $\mathrm{H}$. Characterization of p53 gene mutations in basal-cell carcinomas: Comparison between sun-exposed and lessexposed skin areas. Int J Cancer. 1996; 65: 778-80.

37 Moriwaki S, Yagi T, Nishigori C, Imamura S, Takebe $\mathrm{H}$ Analysis of $\mathrm{N}$-methyl-N-nitrosourea-induced mutations in a shuttle vector plasmid propagated in mouse $\mathrm{O}^{6}$ methylguanine-DNA methyltransferase-deficient cells in comparison with proficient cells. Cancer Res. 1991; 51: 6219-23.

38 Saffhill R, Margison GP, O'Connor PJ. Mechanisms of carcinogenesis induced by alkylating agents. Biochim Biophys Acta. 1985; 823: 111-45.

39 Haracska L, Prakash L, Prakash S. Role of human DNA polymerase kappa as an extender in translesion synthesis. Proc Natl Acad Sci USA. 2002; 99: 16000-5.

40 Maher VM, Yang JL, McCormick JJ. Ability of adducts 
formed in a shuttle vector by reactive metabolites of 1nitropyrene and benzo $[a]$ pyrene to induce mutations when the plasmid replicates in human cells. Acta Biol Hung. 1990; 41: 173-86.

41 Mah MC, Maher VM, Thomas H, Reid TM, King CM, McCormick JJ. Mutations induced by aminofluoreneDNA adducts during replication in human cells. Carcinogenesis. 1989; 10: 2321-8.

42 Kawanishi M, Enya T, Suzuki H, Takebe H, Matsui S, Yagi T. Mutagenic specificity of a derivative of 3nitrobenzanthrone in the supF shuttle vector plasmids. Chem Res Toxicol. 1998; 11: 1468-73.

43 Nishida H, Kawanishi M, Takamura-Enya T, Yagi T. Mutagenic specificity of N-acetoxy-3-aminobenzanthrone, a major metabolically activated form of 3nitrobenzanthrone, in shuttle vector plasmids propagated in human cells. Mutat Res. 2008; 654: 82-7.

44 Chiapperino D, Kroth H, Kramarczuk IH, Sayer JM, Masutani C, Hanaoka F, Jerina DM, Cheh AM. Preferential misincorporation of purine nucleotides by human DNA polymerase eta opposite benzo[a]pyrene 7,8-diol 9,10-epoxide deoxyguanosine adducts. J Biol Chem. 2002; 277: 11765-71.

45 Kirouac KN, Basu AK, Ling H. Replication of a carcinogenic nitropyrene DNA lesion by human Y-family DNA polymerase. Nucleic Acids Res. 2013; 41: 2060-71.

46 Taylor JS. New structural and mechanistic insight into the A-rule and the instructional and non-instructional behavior of DNA photoproducts and other lesions. Mutat Res. 2002; 510: 55-70.

47 Minko IG, Kozekov ID, Harris TM, Rizzo CJ, Lloyd RS, Stone MP. Chemistry and biology of DNA containing 1,N(2)-deoxyguanosine adducts of the alpha, beta-unsaturated aldehydes acrolein, crotonaldehyde, and 4-hydroxynonenal. Chem Res Toxicol. 2009; 22: 759-78.

48 Voulgaridou GP, Anestopoulos I, Franco R, Panayiotidis MI, Pappa A. DNA damage induced by endogenous aldehydes: current state of knowledge. Mutat Res. 2011; 711: 13-27.

49 Matsuda T, Yagi T, Kawanishi M, Matsui S, Takebe H. Molecular analysis of mutations induced by 2-chloroacetaldehyde, the ultimate carcinogenic form of vinyl chloride, in human cells using shuttle vectors. Carcinogenesis. 1995; 16: 2389-94.

50 Kawanishi M, Matsuda T, Sasaki G, Yagi T, Matsui S, Takebe H. A spectrum of mutations induced by crotonaldehyde in shuttle vector plasmids propagated in human cells. Carcinogenesis. 1998; 19: 69-72.

51 Matsuda T, Kawanishi M, Yagi T, Matsui S, Takebe H. Specific tandem GG to TT base substitutions induced by acetaldehyde are due to intra-strand crosslinks between adjacent guanine bases. Nucleic Acids Res. 1998; 26: 1769-74.

52 Kawanishi M, Matsuda T, Nakayama A, Takebe H, Matsui S, Yagi T. Molecular analysis of mutations induced by acrolein in human fibroblast cells using sup F shuttle vector plasmids. Mutat Res. 1998; 417: 65-73.

53 Murata-Kamiya N, Kamiya H, Kaji H, Kasai H. Glyoxal, a major product of DNA oxidation, induces mutations at G:C sites on a shuttle vector plasmid replicated in mammalian cells. Nucleic Acids Res. 1997; 25: 1897-902.

54 Murata-Kamiya N, Kamiya H, Kaji H, Kasai H. Methylglyoxal induces $\mathrm{G}: \mathrm{C}$ to $\mathrm{C}: \mathrm{G}$ and $\mathrm{G}: \mathrm{C}$ to $\mathrm{T}: \mathrm{A}$ transversions in the supF gene on a shuttle vector plasmid replicated in mammalian cells. Mutat Res. 2000; 468: 173-82.

55 Snyder R, Hedli CC. An overview of benzene metabolism. Environ Health Perspect. 1996; 104: 1165-71.

56 Nakayama A, Noguchi Y, Mori T, Morisawa S, Yagi T. Comparison of mutagenic potentials and mutation spectra of benzene metabolites using sup $\mathrm{F}$ shuttle vectors in human cells. Mutagenesis. 2004; 19: 91-7.

57 Nakayama A, Koyoshi S, Morisawa S, Yagi T. Comparison of the mutations induced by $p$-benzoquinone, a benzene metabolite, in human and mouse cells. Mutat Res. 2000; 470: 147-53.

58 Sharma S, Helchowski CM, Canman CE. The roles of DNA polymerase $\zeta$ and the Y family DNA polymerases in promoting or preventing genome instability. Mutat Res. 2013; 743-744: 97-110.

59 Sale JE, Lehmann AR, Woodgate R. Y-family DNA polymerases and their role in tolerance of cellular DNA damage. Nat Rev Mol Cell Biol. 2012; 13: 141-52.

60 Sawai T, Kawanishi M, Takamura-Enya T, Yagi T. Establishment of a method for analyzing translesion DNA synthesis across a single bulky adduct in human cells. Genes Environ. 2009; 31: 24-30.

61 Punchihewa C, Inoue A, Hishiki A, Fujikawa Y, Connelly M, Evison B, Shao Y, Heath R, Kuraoka I, Rodrigues P, Hashimoto H, Kawanishi M, Sato M, Yagi T, Fujii N. Identification of small molecule proliferating cell nuclear antigen (PCNA) inhibitor that disrupts interactions with PIP-box proteins and inhibits DNA replication. J Biol Chem. 2012; 287: 14289-300.

62 Kawanishi M, Fujikawa Y, Ishii H, Nishida H, Higashigaki Y, Kanno T, Matsuda T, Takamura-Enya T, Yagi T. Adduct formation and repair, and translesion DNA synthesis across the adducts in human cells exposed to 3-nitrobenzanthrone. Mutat Res. 2013; 753: 93-100. 